\title{
Physician's recommendation and explanation is important in the initiation and maintenance of allergen immunotherapy
}

This article was published in the following Dove Press journal:

Patient Preference and Adherence

I March 2017

Number of times this article has been viewed

\section{Young-Hee Nam \\ Soo-Keol Lee}

Department of Internal Medicine, College of Medicine, Dong-A University, Busan, Republic of Korea
Correspondence: Soo-Keol Lee Department of Internal Medicine, College of Medicine, Dong-A University, 26 Daesingongwon-ro, Seo-gu, Busan 602-7I5, Republic of Korea

$\mathrm{Tel}+825 \mathrm{I} 2402810$

Fax +82 5I 2425852

Email skleeai@dau.ac.kr
Background: Allergen immunotherapy (AIT) is currently the only immune-modifying treatment for allergic disease. The clinical efficacy of AIT for the treatment of allergic rhinitis and bronchial asthma is well documented. However, many factors including inconvenience, cost, side effects, and adherence influence the initiation and persistence of AIT, and patients lack knowledge and have misconceptions about the treatment.

Objective: We evaluated the knowledge, attitude, and satisfaction of patients who received AIT. Methods: We conducted a retrospective analysis of medical records of 167 patients who received AIT, and compared the clinical characteristics between conventional immunotherapy (CIT) and rush immunotherapy (RIT). Ninety-nine patients completed a questionnaire survey.

Results: Of the total 167 patients, $65.9 \%(\mathrm{n}=110)$ were treated with CIT and $34.1 \%(\mathrm{n}=57)$ with RIT. More than half of the patients (68.7\%) initiated AIT according to their physician's recommendation. Frequent hospital visits were the main barrier for persistence of AIT. RIT patients were younger and started AIT earlier than CIT patients. The majority (77\%) of patients who received AIT were satisfied, with no significant difference between CIT and RIT groups. RIT and fewer allergens used in AIT were related with preference for AIT to pharmacotherapy. The longer duration of AIT was associated with higher treatment satisfaction.

Conclusion: A majority of patients initiated AIT by the physician's recommendation and were satisfied with treatment regardless of CIT or RIT schedule. Adequate patient education and a strict patient-physician relationship in early AIT period could improve the effectiveness and compliance of AIT.

Keywords: allergen, immunotherapy, compliance

\section{Introduction}

Atopic diseases including allergic rhinitis, rhinoconjunctivitis, and asthma are chronic medical conditions that significantly affect patient quality of life and lead to substantial costs for medical care. ${ }^{1}$ Allergen immunotherapy (AIT), together with allergen avoidance and pharmacotherapy, is a cornerstone in the management of allergic respiratory diseases. AIT is the only therapy able to affect the natural course of allergy, not shared by medical treatment, and the benefits include persistence of the clinical benefit after discontinuation of AIT, prevention of the onset of new sensitizations, and sustained effect on the progression of allergic disease. ${ }^{2}$ Its clinical efficacy has been well documented. ${ }^{3,4}$ At least 3 years of treatment is required to obtain the long-term benefits and disease-modifying effects of AIT. ${ }^{5}$

Despite its effectiveness, AIT has been replaced to some degree by symptomatic therapy. Moreover, treatment persistence and compliance of AIT are far from optimal. ${ }^{6-9}$ 
Recent sales data provided by manufacturers showed a discontinuation rate of $90 \%$ in patients undergoing sublingual immunotherapy (SLIT) at 3 years after prescription. ${ }^{6}$ Many factors influence whether patients initiate and complete the recommended course of AIT, including patient-associated factors such as age, concurrent health problems, change of residence, and immunotherapy-associated factors (like cost, inconvenience, lack of effectiveness, and side effects). ${ }^{7-11}$ Inconvenience is one of the most frequent reasons for not choosing and discontinuing AIT. ${ }^{12}$ Rush immunotherapy (RIT) can lessen the duration and hospital visits associated with administration of AIT during the build-up phase compared to conventional immunotherapy (CIT).

Patients' knowledge and expectations have a decisive impact on their compliance and the success of treatment in any chronic conditions, including allergic diseases. ${ }^{13}$ However, patients lack knowledge and have misconceptions about the treatment, with regard to treatment process, duration, and safety. ${ }^{14,15}$ We evaluated the knowledge, attitude, and satisfaction of the patients who received AIT.

\section{Methods \\ Design}

We conducted a retrospective analysis of medical records of 167 patients who were prescribed $\mathrm{AIT}^{8}$ for allergic rhinitis, asthma, and atopic dermatitis at Dong-A University Hospital from May 2002 to May 2015. CIT was started in 2002 and RIT in 2012. The patients who received subcutaneous immunotherapy (SCIT) were only included and those who received SLIT or bee venom immunotherapy were excluded. Between May and August 2015, a self-administered, 14-item questionnaire was given to the patients who had currently received AIT and were undergoing treatment for more than 1 year. Treatment satisfaction was graded on a 5-point scale, ranging from very dissatisfied ( 0 points) to very satisfied ( 5 points).

We analyzed and compared the clinical characteristics and the results of questionnaire survey between those who received CIT and RIT. This study was approved by the Institutional Review Board of Dong-A University Hospital (consent number 15-195).

\section{Immunotherapy}

All the patients provided written informed consent after being briefed about the treatment process, benefits, and risks before AIT initiation. RIT schedule was started 11 years later after the initiation of CIT at Dong-A University Hospital. Since the initiation of RIT in 2012, AIT was conducted by either CIT or RIT during build-up phase in accordance with the patient's choice. The CIT build-up phase consisted of one or two injections during each weekly outpatient clinic visit. ${ }^{8}$ In the RIT build-up phase, incremental doses of allergen were administered at intervals that varied from 60 to 120 minutes over a period of 3-4 days. ${ }^{8}$ After the target therapeutic dose (maintenance dose) was achieved, an injection was administered monthly 2 weeks later. When the patients developed systemic adverse reactions to AIT during the build-up phase, they were treated appropriately and the schedule was modified according to the severity of the reactions. Mild reactions were defined as localized skin and subcutaneous symptoms only such as erythema, itching, and localized urticaria, while moderate and severe reactions included generalized skin and cutaneous symptoms, respiratory, cardiovascular, and gastrointestinal involvement such as hypoxia, hypotension, and neurologic compromise. When the reactions were mild, administrations were done as planned. In cases of moderate or severe reactions, the next injection comprised the same or the previous dose of allergen followed by slow incremental increase until the maintenance dose was achieved. The injection was given by a trained nurse. The patients could consult a physician whenever problems arose during AIT. Noncompliance was defined as the AIT that was not continued for more than 2 weeks during a build-up phase, and more than 2 months during a maintenance phase for the initial 12 months. The treatment was said to be discontinued when the total duration of maintenance period was less than 3 years. The duration of AIT was determined from the maintenance phase.

\section{Statistical analysis}

Quantitative and qualitative results are given by the mean \pm standard deviation and absolute numbers or frequencies, respectively. Descriptive statistics were performed using SPSS software version 12.0 (SPSS Inc., Chicago, IL, USA). Statistical significance was assessed using the Mann-Whitney $U$-test for continuous variables and the Fisher's exact test for categorical variables. $P$-values $<0.05$ were considered to indicate statistical significance.

\section{Results}

\section{Patient characteristics}

A total of 167 patients were treated with CIT $(n=110,65.9 \%)$ and RIT ( $\mathrm{n}=57,34.1 \%)$. Of the total 110 CIT patients, 29 (26\%) started CIT before RIT conduction, and 81 (74\%) after RIT conduction. The CIT and RIT groups comprised 62 males $(56.4 \%)$ and 32 males (56.1\%), respectively; of the 167 (94\%) patients, 157 were adults and only 10 were 
children or adolescents (age range: $11-17$ years). The mean age (38.9 \pm 14.2 years vs $32.5 \pm 12.8$ years, $P=0.005$ ) and mean age at the start of AIT (36.0 \pm 14.2 years vs $30.6 \pm 13.1$ years, $P=0.019)$ were significantly higher in the CIT group than in the RIT group. The age at onset of the allergic disease was not different significantly between the two groups. In the CIT and RIT groups, cases of bronchial asthma were $39(35.5 \%)$ and $19(33.3 \%)$ and cases of allergic rhinitis were $103(93.6 \%)$ and $51(89.5 \%)$, respectively (Table 1).

Ninety-nine patients completed the questionnaire (61 in the CIT group and 39 in the RIT group). Sixty-eight patients did not perform the survey; 10 refused the questionnaire survey, 2 finished the AIT after 3 years of treatment, 14 were referred to other hospitals because of change of residence, and 42 discontinued AIT. There were no significant differences in any of the clinical characteristics between the responders in both the groups (data not shown).

\section{Comparison between CIT and RIT}

The most common allergens used in AIT were house dust mites (Dermatophagoides pteronyssinus and/or Dermatophagoides farinae) followed by tree pollens and weed pollens. The duration of AIT was significantly longer in CIT patients than in RIT patients $(24.7 \pm 22.3$ months vs $14.7 \pm 16.8$ months, $P=0.003$ ). The proportion of patients with more than 3-year AIT duration were more in the CIT than in the RIT group; however, the proportion of patients with less than 3-year AIT duration were similar between the two groups (data not shown). Forty-two (25.1\%) patients discontinued AIT with less than 3-year treatment, and only three of them were children or adolescents. There was no significant difference in the discontinuation rate between the two groups. About $70 \%$ of patients who discontinued AIT had no special reason for discontinuation or had no follow-up visit. During the

Table I Clinical characteristics of the patients

\begin{tabular}{|c|c|c|c|}
\hline Clinical characteristics & $\begin{array}{l}\text { CIT group } \\
\mathrm{n}=\mathrm{I} \mid \mathrm{O}(\%)\end{array}$ & $\begin{array}{l}\text { RIT group } \\
\mathrm{n}=57(\%)\end{array}$ & $P$-value \\
\hline Age, ${ }^{\mathrm{a}}$ years & $38.9 \pm 14.2$ & $32.5 \pm 12.8$ & 0.005 \\
\hline Males & $62(56.4)$ & $32(56.1)$ & $>0.9$ \\
\hline $\begin{array}{l}\text { Age at onset of allergic } \\
\text { disease, }{ }^{\text {a }} \text { years }\end{array}$ & $28.1 \pm 16.1$ & $24.2 \pm 14.0$ & 0.136 \\
\hline Age at start of AIT, ${ }^{a}$ years & $36.0 \pm 14.2$ & $30.6 \pm 13.1$ & 0.019 \\
\hline \multicolumn{4}{|l|}{ Allergic diseases } \\
\hline Bronchial asthma & $39(35.5)$ & $19(33.3)$ & 0.865 \\
\hline Allergic rhinitis & 103 (93.6) & 51 (89.5) & 0.37 \\
\hline Atopic dermatitis & $10(9.1)$ & $12(2||)$. & 0.051 \\
\hline
\end{tabular}

Note: Data are presented as mean \pm SD.

Abbreviations: AIT, allergen immunotherapy; CIT, conventional immunotherapy; RIT, rush immunotherapy; SD, standard deviation. build-up phase, CIT patients showed significantly higher noncompliance rate $(25.5 \%$ vs $3.5 \%, P<0.001)$ than RIT patients (Table 2), while there was no difference during the maintenance phase (data not shown). Although adverse reactions during build-up phase were not significantly different, dyspnea and anaphylaxis, defined as the clinical criteria previously, ${ }^{16}$ were significantly more frequent in the RIT group than in the CIT group.

\section{Questionnaire survey}

\section{Knowledge and attitude toward AIT}

A total of $68.7 \%$ of the patients initiated AIT by the physician's recommendation and not by their own decision, which was not different between the patients of CIT and RIT groups (67.2\% vs $71.1 \%)$. Most of the patients (97\%) answered they were provided with the information about AIT, such as the method, effect and risk, duration of the treatment, cost, and adverse reactions, by their physicians before AIT initiation (96.7\% vs 97.4\%) and knew the allergens injected with AIT (98.4\% vs 100\%). More patients undergoing CIT expected complete cure of allergic disease (31.1\% vs $23.7 \%$ ) and improvement of symptoms by more than $50 \%(44.3 \%$ vs $42.1 \%)$ than those undergoing RIT (Table 3).

Table 2 Comparison of the practice between conventional and rush AIT

\begin{tabular}{|c|c|c|c|}
\hline & $\begin{array}{l}\text { CIT group } \\
n=110 \text { (\%) }\end{array}$ & $\begin{array}{l}\text { RIT group } \\
n=57(\%)\end{array}$ & $P$-value \\
\hline \multicolumn{4}{|l|}{ Allergen } \\
\hline House dust mite & $74(67.3)$ & $45(78.9)$ & 0.149 \\
\hline Tree pollen & 49 (44.5) & $24(42.1)$ & 0.87 \\
\hline Grass pollen & $4(3.6)$ & $4(7)$ & 0.447 \\
\hline Weed pollen & $23(20.9)$ & II (19.3) & 0.843 \\
\hline Dog dander & $4(3.6)$ & $5(8.8)$ & 0.276 \\
\hline Cat dander & $5(4.5)$ & $3(5.3)$ & $>0.9$ \\
\hline Fungi & I (0.9) & 0 & $>0.9$ \\
\hline Number of allergens ${ }^{a}$ & $2.7 \pm 1.1$ & $3.0 \pm 1.4$ & 0.102 \\
\hline Duration of AIT, a,b months & $24.7 \pm 22.3$ & $14.7 \pm 16.8$ & 0.003 \\
\hline Discontinuation & $28(25.5)$ & $14(24.6)$ & $>0.9$ \\
\hline Noncompliance $^{c}$ & $28(25.5)$ & $2(3.5)$ & $<0.001$ \\
\hline Frequency of noncompliance ${ }^{c}$ & $0.6 \pm 1.2$ & $0.3 \pm 0.6$ & 0.014 \\
\hline Adverse reactions $^{c}$ & $32(29.1)$ & $22(38.6)$ & 0.226 \\
\hline Itching & 14 (12.7) & $8(14)$ & 0.813 \\
\hline Rash or swelling & $9(8.2)$ & $5(8.8)$ & $>0.9$ \\
\hline Urticaria and/or angioedema & II (I0) & $8(14)$ & 0.45 \\
\hline Dyspnea & $4(3.6)$ & $8(14)$ & 0.023 \\
\hline Anaphylaxis & 0 & $8(8.8)$ & 0.004 \\
\hline Other & $2(1.8)$ & $10(17.5)$ & $<0.001$ \\
\hline
\end{tabular}

Notes: ${ }^{\mathrm{a} D a t a}$ are presented as mean $\pm \mathrm{SD}$; bduration of AIT was determined from maintenance phase; 'data presented are during build-up phase.

Abbreviations: AIT, allergen immunotherapy; CIT, conventional immunotherapy; RIT, rush immunotherapy; SD, standard deviation. 
Table 3 Knowledge and attitude toward allergen immunotherapy

\begin{tabular}{|c|c|c|c|}
\hline & $\begin{array}{l}\text { CIT group } \\
n=6 I(\%)\end{array}$ & $\begin{array}{l}\text { RIT group } \\
n=38(\%)\end{array}$ & $P$-value \\
\hline Initiation of AIT & & & 0.824 \\
\hline Patient's own decision & $20(32.8)$ & II (28.9) & \\
\hline Physician's recommendation & $4 \mathrm{I}(67.2)$ & $27(7 \mathrm{I} .1)$ & \\
\hline Personal insurance & $41(67.2)$ & $30(78.9)$ & 0.255 \\
\hline $\begin{array}{l}\text { Information provided by the } \\
\text { physician before AIT start }\end{array}$ & $58(96.7)$ & $37(97.4)$ & $>0.9$ \\
\hline Awareness of allergens used in AIT & $60(98.4)$ & $38(100)$ & $>0.9$ \\
\hline Goal of AIT & & & 0.535 \\
\hline Complete cure & $19(31.1)$ & $9(23.7)$ & \\
\hline $\begin{array}{l}\text { Improvement of } \\
\text { symptoms }>50 \%\end{array}$ & $27(44.3)$ & $16(42.1)$ & \\
\hline Any improvement of symptoms & $15(24.6)$ & $13(34.2)$ & \\
\hline Barriers of AIT persistence & & & 0.775 \\
\hline Frequent hospital visit & $34(55.7)$ & $21(55.3)$ & \\
\hline Cost & $15(24.6)$ & $14(36.8)$ & \\
\hline Lack of efficacy & $13(2 \mid .3)$ & $8(21.1)$ & \\
\hline Concern for adverse effects & $8(13.1)$ & $3(7.9)$ & \\
\hline $\begin{array}{l}\text { Reporting the adverse effects to } \\
\text { the physician/nurse }\end{array}$ & $16(84.2)$ & $17(94.4)$ & 0.604 \\
\hline
\end{tabular}

Abbreviations: AIT, allergen immunotherapy; CIT, conventional immunotherapy; RIT, rush immunotherapy.

Frequent hospital visits were the main barrier to AIT persistence, followed by cost, lack of efficacy, and concern for adverse events, with no significant differences between the two groups (Table 3). The reasons for the initiation of CIT were difficulty for admission (61.7\%), no specific reason (20\%), concern for adverse events $(6.7 \%)$, and expectation of better effect than RIT (5\%). Patients chose RIT instead of CIT because of the need for frequent hospital visits (55.3\%), expectation of faster effect (28.9\%), and expectation of better effect than CIT (13.2\%; data not shown).

\section{Treatment results with AIT}

The majority (77\%) of the patients were satisfied with AIT, and none were very dissatisfied with AIT. More patients undergoing RIT preferred AIT to pharmacotherapy than those undergoing CIT ( $73.8 \%$ vs $88.9 \%, P=0.118)$. There was no significant difference in treatment satisfaction between the CIT and RIT groups (Table 4). More proportion of patients who decided on their own to initiate AIT were very satisfied than those who initiated AIT on the recommendation of their physician (Figure 1). Patient satisfaction grew with a longer duration of AIT (Figure 2). However, there was no significant difference between those with more than 3 years of treatment and those with less than 3 years (Figure 3). Patients with allergic rhinitis were more satisfied than those without $(80 \%$ vs $32.5 \% ; P=0.016$, data not shown). RIT and fewer allergens used in AIT were associated with greater preference for
Table 4 Treatment results and satisfaction with allergen immunotherapy

\begin{tabular}{|c|c|c|c|}
\hline & $\begin{array}{l}\text { CIT group } \\
n=6 I(\%)\end{array}$ & $\begin{array}{l}\text { RIT group } \\
n=\mathbf{3 8}(\%)\end{array}$ & $P$-value \\
\hline Satisfaction & & & 0.42 \\
\hline Very satisfied & $14(23)$ & $9(23.7)$ & \\
\hline Satisfied & $35(57.4)$ & I 8 (47.4) & \\
\hline Neutral & II (I8) & $8(2 I . I)$ & \\
\hline Dissatisfied & I (I.6) & $3(7.9)$ & \\
\hline Very dissatisfied & 0 & 0 & \\
\hline $\begin{array}{l}\text { Preference of AIT } \\
\text { to pharmacotherapy }\end{array}$ & $45(73.8)$ & 32 (88.9) & 0.118 \\
\hline Medical costs & & & $0.34 I$ \\
\hline Decreased & I5 (24.6) & $7(18.9)$ & \\
\hline Same/not changed & $35(57.4)$ & $23(59.5)$ & \\
\hline Increased & II (18) & $8(21.6)$ & \\
\hline Use of medication & & & 0.839 \\
\hline Usually daily & $19(31.1)$ & $10(26.3)$ & \\
\hline Intermittent & $24(39.3)$ & $15(39.5)$ & \\
\hline No use & $18(29.5)$ & $13(34.2)$ & \\
\hline
\end{tabular}

Abbreviations: AIT, allergen immunotherapy; CIT, conventional immunotherapy; RIT, rush immunotherapy.

AIT compared to pharmacotherapy (Figure 4). Twenty-two percent of the total patients had their medical costs reduced and $31 \%$ did not take any medications for allergic diseases, but there was no significant difference between the CIT and RIT groups (Table 4).

\section{Discussion}

AIT plays an important role in the treatment of allergic diseases, and is associated with favorable outcomes. However, the use of the therapy is hindered by its long treatment duration. Patient adherence to treatment of chronic diseases is estimated to be $50 \%$. Adherence to AIT varies widely, ranging from $13 \%$ to $89 \%$ in SCIT, ${ }^{17}$ and only $18 \%$ of patients reached the minimally required duration of treatment of 3 years in one real-life study. ${ }^{18}$

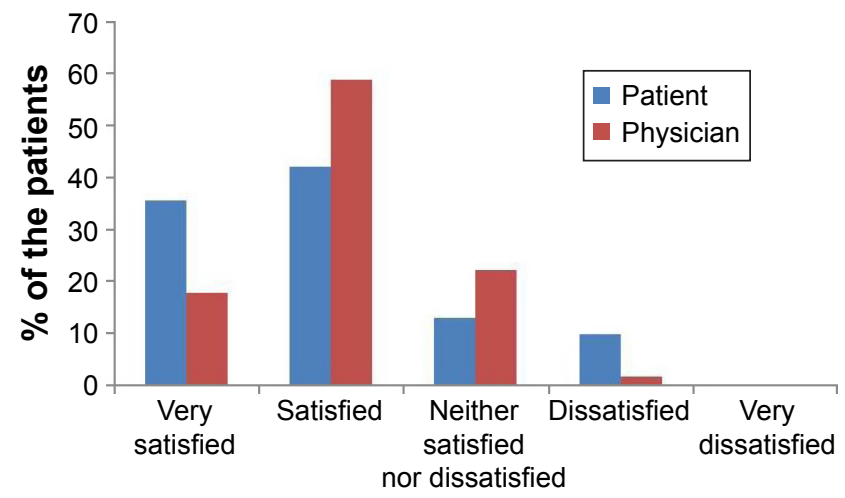

Figure I Distribution of treatment satisfaction according to allergen immunotherapy initiation by the patient or the physician. 


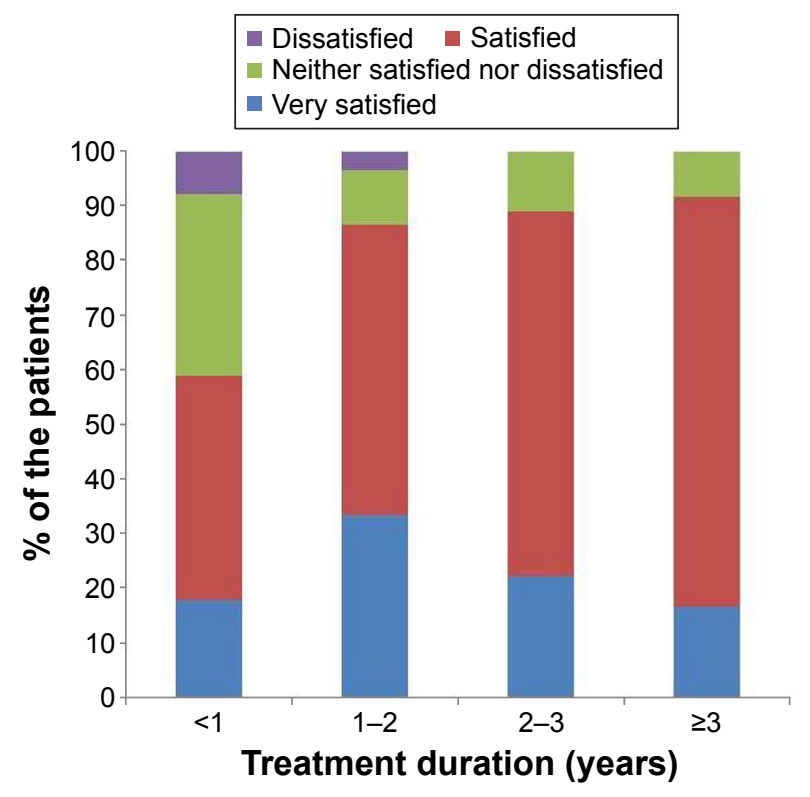

Figure 2 Distribution of treatment satisfaction according to allergen immunotherapy duration.

In this study, patients receiving SCIT were only included, and the data were analyzed and compared between CIT and RIT groups. RIT shortens the build-up phase compared with CIT and minimizes inconvenience associated with AIT, but exhibits a higher incidence of adverse systemic reactions. After 11 years of clinical experience with CIT, RIT was introduced in our hospital. This might indicate that CIT duration was longer than RIT duration. Patients had difficulties with scheduling time for their injection during business or school hours. Younger patients, especially students or employees, preferred RIT to CIT, and RIT patients were younger than
CIT patients in our study. Many efforts to increase adherence have been attempted, including various administration routes, accelerated immunotherapy schedule, and frequent monitoring..$^{19,20}$ RIT slightly improved the compliance rate among the patients compared with CIT. ${ }^{19}$ The duration of the build-up phase for CIT was about three times longer than for RIT (data not shown); however, the discontinuation rate and treatment satisfaction were similar between the groups. RIT was associated with a higher preference for AIT in relation to pharmacotherapy. RIT is associated with an increased risk of systemic reactions, with most of them not being severe. ${ }^{8}$ In this study, total adverse reactions and severe reactions were more common in the RIT than in the CIT group. However, no patient stopped AIT because of associated adverse reactions.

Treatment satisfaction was associated with longer treatment duration and patient initiation of AIT. The duration of AIT was longer in CIT than in RIT group due to the later initiation of RIT; however, there was no significant difference in treatment satisfaction between the two groups. The proportion of patients who were very satisfied was higher when the decision to start AIT was the patient's own but not physician's recommendation. The proportion of patients who were satisfied with AIT significantly increased as the duration of AIT became longer, being markedly higher after 1 year of treatment and remaining high until 3 years of treatment. Sade et a ${ }^{15}$ reported that patients in the first 6 months of AIT had more knowledge about AIT than those who had been undergoing long-term treatment. One-year SLIT in pediatric patients with allergic rhinitis sensitized to house

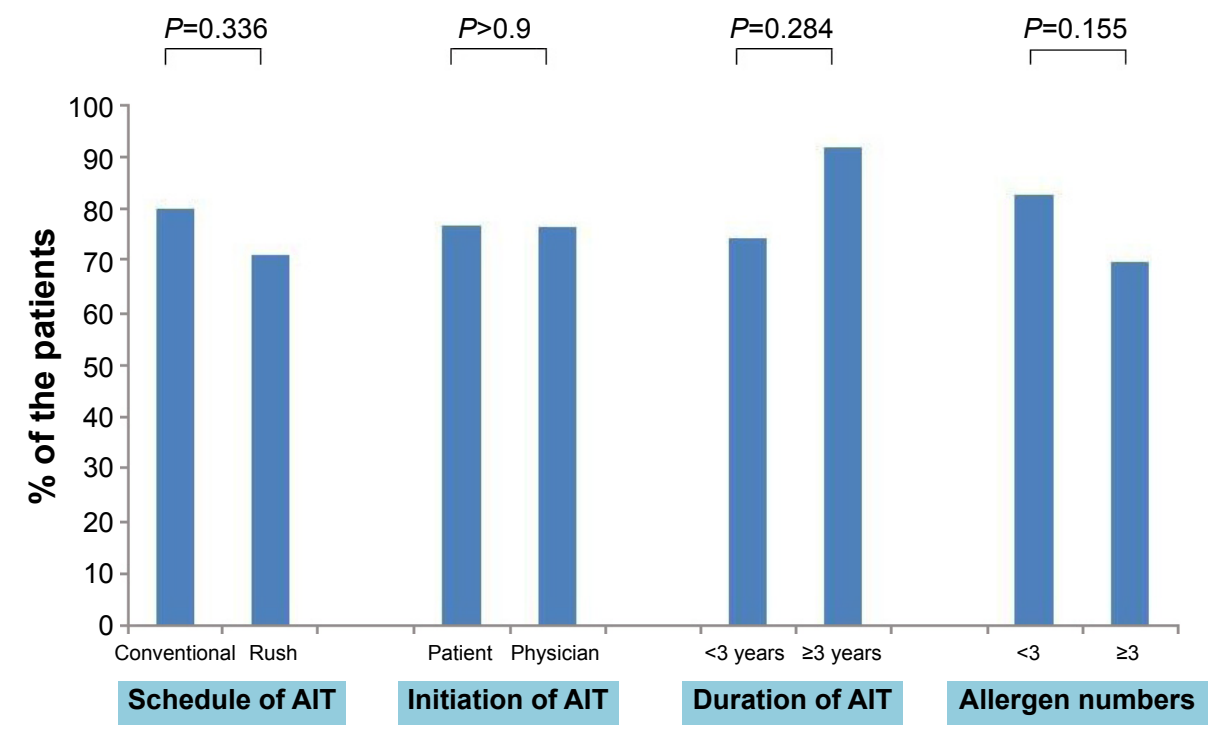

Figure 3 Proportion of the patients who were satisfied with the allergen immunotherapy (AIT). 


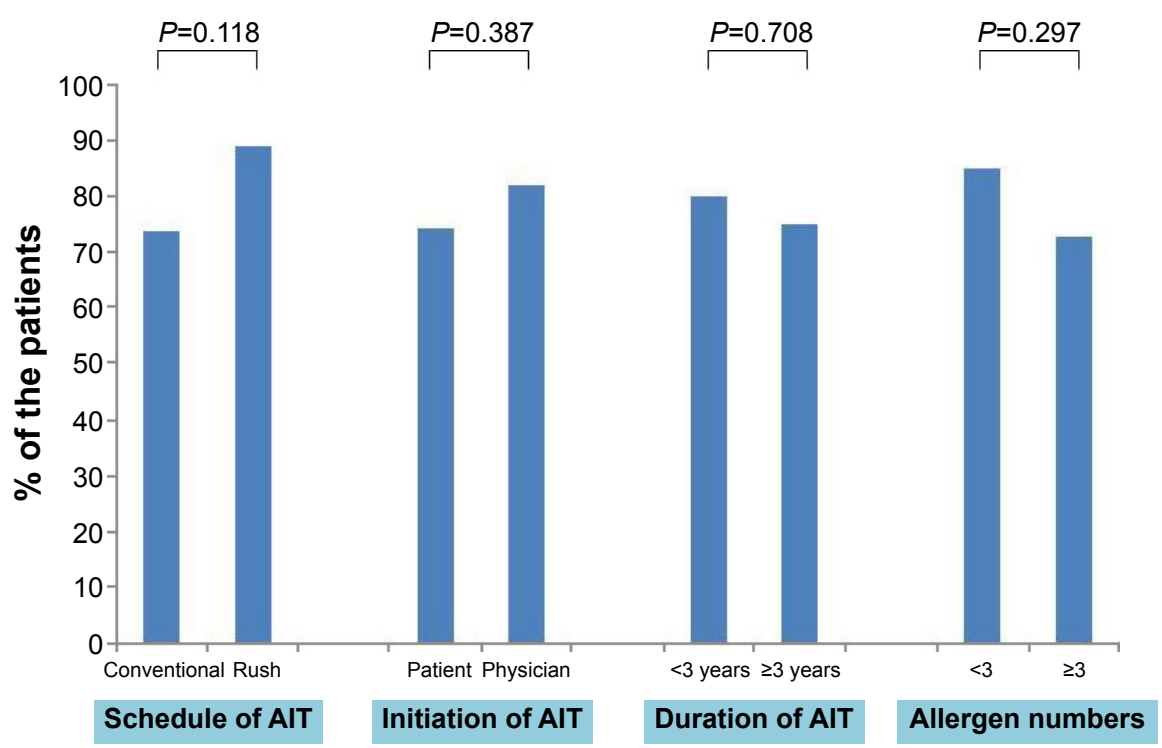

Figure 4 Proportion of patients who preferred allergen immunotherapy (AIT) to pharmacotherapy.

dust mites improved subjective symptoms and decreased medication use. ${ }^{21}$ Postmarketing surveys reported that the observation itself can affect the compliance with AIT, which means when patients are aware that their compliance with treatment is recorded, they tend to be more adherent. ${ }^{6}$ These findings suggest that more communication and closer physician-patient relationship before AIT, and especially in early phase of AIT, could improve the adherence and efficacy of AIT.

The main factor for discontinuation of AIT was cost, when health insurance is inadequate or does not exist. ${ }^{10,11}$ About $70 \%$ of the patients in this study had personal insurance; for them, the time consumed by the frequent hospital visits and long treatment duration were the main barriers to AIT adherence. RIT might reduce treatment duration, particularly build-up phase and hospital visits, and its related costs.

Patients might lack knowledge and have misconceptions about AIT, ${ }^{14,15}$ although a real-life study involving a large patient population reported that the majority of patients had an adequate knowledge and perceptions about AIT. ${ }^{22}$ Most patients had greater and adequate knowledge and perceptions about AIT in our study. Furthermore, physicians also had good $^{23,24}$ or poor ${ }^{25}$ perceptions about AIT, and there were significant differences between physicians who had taken and not taken the training in the field of allergy. ${ }^{26}$ Physicians who had taken an allergy rotation during resident training programs had a tendency to view AIT as effective and to have referral patterns for allergic diseases to the allergist compared with those who had not taken. ${ }^{26}$ In another Korean study, ${ }^{27}$ less than half of the patients diagnosed with allergic rhinoconjunctivitis had reported they had ever heard of AIT; of those, $40 \%$ had ever discussed AIT with physicians, and half of the physicians were allergists. These findings indicate that education about AIT is needed for both patients and physicians.

This study has some limitations. First, the AIT duration was not similar between the CIT and RIT groups. Second, the patients undergoing AIT for more than 3 years were part of the total study patients. Finally, the questionnaire survey was not conducted on all the study patients. However, the present study findings are generally consistent with the previous studies on perception and adherence to AIT. In addition, we analyzed and compared the clinical characteristics of AIT between CIT and RIT in real-world clinical practice.

\section{Conclusion}

Most patients undergoing CIT and RIT were informed about treatment before the start of AIT; they understood and were satisfied with the treatment procedure. Active patient education and strict patient-physician relationship in early AIT period would improve the effectiveness and compliance of AIT.

\section{Acknowledgment}

This work was supported by the Dong-A University research fund.

\section{Disclosure}

The authors report no conflicts of interest in this work. 


\section{References}

1. Dykewicz MS, Fineman S, Skoner DP, et al. Diagnosis and management of rhinitis: complete guidelines of the Joint Task Force on Practice Parameters in Allergy, Asthma and Immunology. American Academy of Allergy, Asthma, and Immunology. Ann Allergy Asthma Immunol. 1998;81(5 Pt 2):478-518.

2. Passalacqua G. Specific immunotherapy: beyond the clinical scores. Ann Allergy Asthma Immunol. 2011;107(5):401-406.

3. Lower T, Henry J, Mandik L, Janosky J, Friday GA Jr. Compliance with allergen immunotherapy. Ann Allergy. 1993;70(6):480-482.

4. van Cauwenberge P, Bachert C, Passalacqua G, et al. Consensus statement on the treatment of allergic rhinitis. European Academy of Allergology and Clinical Immunology. Allergy. 2000;55(2):116-134.

5. Durham SR, Emminger W, Kapp A, et al. Long-term clinical efficacy in grass pollen-induced rhinoconjunctivitis after treatment with SQ-standardized grass allergy immunotherapy tablet. J Allergy Clin Immunol. 2010;125(1):131-138.e1-e7.

6. Senna G, Lombardi C, Canonica GW, Passalacqua G. How adherent to sublingual immunotherapy prescriptions are patients? The manufacturers' viewpoint. J Allergy Clin Immunol. 2010;126(3):668-669.

7. Senna G, Ridolo E, Calderon M, Lombardi C, Canonica GW, Passalacqua G. Evidence of adherence to allergen-specific immunotherapy. Curr Opin Allergy Clin Immunol. 2009;9(6):544-548.

8. Cox L, Nelson H, Lockey R, et al. Allergen immunotherapy: a practice parameter third update. J Allergy Clin Immunol. 2011;127(Suppl 1): S1-S55.

9. Hankin CS, Lockey RF. Patient characteristics associated with allergen immunotherapy initiation and adherence. J Allergy Clin Immunol. 2011;127(1):46-48, 48.e1-e3.

10. Vaswani R, Liu YC, Parikh L, Vaswani S. Inadequate health insurance coverage: a major factor in premature discontinuation of subcutaneous immunotherapy for allergic rhinitis. Ear Nose Throat J. 2011;90(4): 170-173.

11. Vaswani R, Garg A, Parikh L, Vaswani S. Non-adherence to subcutaneous allergen immunotherapy: inadequate health insurance coverage is the leading cause. Ann Allergy Asthma Immunol. 2015;115(3):241-243.

12. Cohn JR, Pizzi A. Determinants of patient compliance with allergen immunotherapy. J Allergy Clin Immunol. 1993;91(3):734-737.

13. Blackwell B. Drug therapy: patient compliance. N Engl J Med. 1973; 289(5):249-252.

14. Sangasapaviliya A, Pholsuwanchai K. Attitude and knowledge of patients with asthma and allergic rhinitis who received allergen immunotherapy in Phramongkutklao Hospital. J Med Assoc Thai. 2010;93 (Suppl 6):S100-S105.
15. Sade K, Berkun Y, Dolev Z, Shalit M, Kivity S. Knowledge and expectations of patients receiving aeroallergen immunotherapy. Ann Allergy Asthma Immunol. 2003;91(5):444-448.

16. Simons FE, Ardusso LR, Bilo MB, et al; World Allergy Organization. World Allergy Organization anaphylaxis guidelines: summary. J Allergy Clin Immunol. 2011;127(3):587-593.e1-e22.

17. Reisacher WR, Visaya JM. Patient adherence to allergy immunotherapy. Curr Opin Otolaryngol Head Neck Surg. 2013;21(3):256-262.

18. Kiel MA, Roder E, Gerth van Wijk R, Al MJ, Hop WC, Rutten-van Mölken MP. Real-life compliance and persistence among users of subcutaneous and sublingual allergen immunotherapy. J Allergy Clin Immunol. 2013;132(2):353-360.e2.

19. More DR, Hagan LL. Factors affecting compliance with allergen immunotherapy at a military medical center. Ann Allergy Asthma Immunol. 2002;88(4):391-394.

20. Vita D, Caminiti L, Ruggeri P, Pajno GB. Sublingual immunotherapy: adherence based on timing and monitoring control visits. Allergy. 2010;65(5):668-669.

21. Han DH, Choi YS, Lee JE, et al. Clinical efficacy of sublingual immunotherapy in pediatric patients with allergic rhinitis sensitized to house dust mites: comparison to adult patients. Acta Otolaryngol. 2012;132 (Suppl 1):S88-S93.

22. Baiardini I, Puggioni F, Menoni S, et al. Patient knowledge, perceptions, expectations and satisfaction on allergen-specific immunotherapy: a survey. Respir Med. 2013;107(3):361-367.

23. Lombardi C, Canonica GW, Passalacqua G. The perception of allergenspecific immunotherapy among chest physicians: an Italian survey. Eur Ann Allergy Clin Immunol. 2014;46(4):132-136.

24. Landi M, Meglio P, Praitano E, Lombardi C, Passalacqua G, Canonica GW. The perception of allergen-specific immunotherapy among pediatricians in the primary care setting. Clin Mol Allergy. 2015; 13(1):15

25. Sikora JM, Tankersley MS; ACAAI Immunotherapy and Diagnostics Committee. Perception and practice of sublingual immunotherapy among practicing allergists in the United States: a follow-up survey. Ann Allergy Asthma Immunol. 2013;110(3):194-197.e4.

26. Baptist AP, Baldwin JL. Physician attitudes, opinions, and referral patterns: comparisons of those who have and have not taken an allergy/ immunology rotation. Ann Allergy Asthma Immunol. 2004;93(3): $227-231$.

27. Skoner DP, Blaiss MS, Dykewicz MS, et al. The Allergies, Immunotherapy, and RhinoconjunctivitiS (AIRS) survey: patients' experience with allergen immunotherapy. Allergy Asthma Proc. 2014;35(3):219-226.
Patient Preference and Adherence

\section{Publish your work in this journal}

Patient Preference and Adherence is an international, peer-reviewed, open access journal that focuses on the growing importance of patient preference and adherence throughout the therapeutic continuum. Patient satisfaction, acceptability, quality of life, compliance, persistence and their role in developing new therapeutic modalities and compounds to optimize

\section{Dovepress}

clinical outcomes for existing disease states are major areas of interest for the journal. This journal has been accepted for indexing on PubMed Central. The manuscript management system is completely online and includes a very quick and fair peer-review system, which is all easy to use. Visit http://www. dovepress.com/testimonials.php to read real quotes from published authors. 